\title{
Does Climate Change Asymmetrically Affect Rice Productivity In India? New Insight From NARDL Cointegration Approach
}

Imran Ali Baig ( $\sim$ ialibaig043@gmail.com )

Aligarh Muslim University https://orcid.org/0000-0002-2087-3621

Abbas Ali Chandio

Sichuan Agricultural University

Md. Abdus Salam

Aligarh Muslim University

\section{Research Article}

Keywords: Rice productivity, Climate Change, Asymmetry, Symmetry, NARDL, India

Posted Date: June 7th, 2021

DOI: https://doi.org/10.21203/rs.3.rs-524765/v1

License: (c) (1) This work is licensed under a Creative Commons Attribution 4.0 International License.

Read Full License 

Insight from NARDL Cointegration approach

\section{Imran Ali Baig ${ }^{*}$, Abbas Ali Chandio², \& Md. Abdus Salam ${ }^{3}$}

${ }^{1,3}$ Department of Economics, Aligarh Muslim University, Aligarh (India),

*Email Id: ialibaig043@gmail.com

${ }^{2}$ College of Economics, Sichuan Agricultural University, District, Chengdu, China

Email: alichandio@sicau.edu.cn 


\section{Abstract:}

This article attempt to answer the question "whether the dynamic relationship between climate change and rice productivity is symmetrical or asymmetrical" using data from 1990-2017 in India. First, we test the symmetrical and long-run dynamic relationship using the Autoregressive Distributed Lags (ARDL) model and test the asymmetrical and cointegration relationship based on Nonlinear Auto-Regressive Distributed Lag (NARDL) technique. The results of the ARDL model indicates that no symmetrical relationship between the variables in long-run. Whereas outcomes of the NARDL bound test reveal that there is long-run asymmetrical impact of climate change on rice productivity. The positive and negative shock of climate change has affected the rice productivity by different magnitude in India. The Wald statistics confirm asymmetric relationship between rice productivity and climate change in the long-run while only short-run asymmetrical relationships exist between rainfall and rice productivity in India.

Furthermore, dynamic multipliers indicate that negative component of rainfall and temperature has a dominant effect over the positive component on rice productivity. To the best of the author's knowledge, no studies have been done to assess both symmetrical and asymmetrical dynamic relationships between climate change and rice productivity using ARDL and NARDL cointegration approaches in India's context. This study will help frame the environmental policies and strategy to cope with climate change in India's agriculture productivity.

Key Words: Rice productivity, Climate Change, Asymmetry, Symmetry, NARDL, India

\section{Introduction}

Since 1990s climate change has been attracting environmentalist and policymaker's attention across the globe due to its long-term harmful impact on agricultural productivity, food product, water supply and livelihoods of rural poor (Artner, 2010; Chavas et al., 2009; Mohorji et al., 2017). Climate change is the results from increasing human activities on the land, including deforestation, land use, urbanisation, increasing population, production and consumption activities to fulfil people's demand for food supply. Climate steadily changes due to global temperature, precipitation, and carbon emission, significantly impacting agricultural productivity and growth (Chandio et al., 2021; Klutse et al., 2021). Agricultural productivity has been decreasing due to the main driver of climate change such as precipitation and warmer temperature (Haile et al., 2017). The gradual increase in temperature is due to the increasing carbon concentration in the atmosphere, mainly caused by high production activities by developed countries. However, increase in temperature, variation in rainfall and frequent occurrence of floods \& droughts are mostly faced by the developing nation, which is situated in the tropical region and relies heavily on agriculture sector (Janjua et al., 2014). Agriculture and its allied activities are sensitive of climate change and other hand it is also contributed on carbon emission (Swaminathan \& Kesavan, 2012). Climate change is harmful to agriculture production and enhances the vulnerability among small and medium farmers whose livelihoods are mainly dependent on agricultural and allied activities (Zakaria et al., 2020). Impact of climate change may vary from region to region based on the geographical location. In case of a developed nation, climate change has a positive impact on agriculture productivity while it deteriorates the performance of agriculture sector in the developing countries (Shujaat Abbas, 2020; Janjua et al., 
crop production and food security in the long in South Asia. Swaminathan \& Kesavan (2012) stated that climate change adversely affected the food production and also location could be change of main food producing areas. The developing nations are more vulnerable than developed countries due to more extensive dependence on agriculture sector for livelihood, lack of technological advancement and lack of adaptation policies of climate change on agriculture production (Praveen \& Sharma, 2020; Warsame, 2021). However, Chandio et al., (2021) stated that the increase in temperature and financial development, respectively has negative and positive impact on cereal production in Pakistan. While Ahsan et al. (2020) demonstrated that energy consumption, labour force, cultivated area and $\mathrm{CO}_{2}$ are the main determinants of agriculture productivity and $\mathrm{CO}_{2}$ positively impact agriculture productivity. Likewise, Warsame (2021) explained mean temperature and $\mathrm{CO}_{2}$ has negatively influenced agriculture productivity in Somalia. Similarly, Coulibaly et.al, (2020) concluded that temperature and drought are the main factors which negatively affect agriculture productivity. The Indian agriculture sector is the most sensitive and exposed area to climate change due to less adaptive capacity to cope with it (Guntukula, 2019). Investigating the impact of climate change on agriculture productivity is of immense importance because more than $50 \%$ population of India primarily depends on agricultural activities for their livelihoods (Pattanayak \& Kumar, 2013). As the changes in environmental factors such as temperature, precipitation, $\mathrm{CO}_{2}$, and rainfall pattern directly affect agriculture productivity (Res et al., 1998), it is indispensable to examine the effect of changes in climatic conditions on agriculture productivity. In India, More than 60 per cent population mainly depends on the agriculture and its allied sectors and Climate change may be the effect of food security by hampering agriculture productivity are not only from one-way but also from multiple-ways. However, the impact of climate change is across the globe and its adverse effects are likely to be more severe under Indian agro-ecological conditions, and climate models predict the severe effect of climate change on the agriculture sector (Bahl, 2015). Clime change has significantly affected the agricultural productivity and foods supply which will be a threat to food security in the country (Moses et al., 2015). The emerging adverse impacts of climatic changes will put pressure on crop productivity particularly rice because they are more sensitive to variation due to climate change and its associated factors (Bahl, 2015). Given the sensitivity of rice to environmental change, especially those related to temperature increases and extended drought periods, copping with the future worldwide demand for rice seems a troublesome task. Furthermore, changes in the length of the growing period because of temperature increments will influence rice yield as well as will move cultivating frameworks from rice towards more appropriate crops with adequate temperature optima (Korres et al., 2017).

India delivers a predominantly remarkable case study for examining how rice may respond to climate change. India

78 is the first largest exportable country of rice in the World which is counted 9.8 million tonnes followed by Thailand 79 (7.5 million tonnes), Vietnam (6.5 million tonnes), Pakistan (4.6 million tonnes) and the USA (3.1 million tonnes). In 


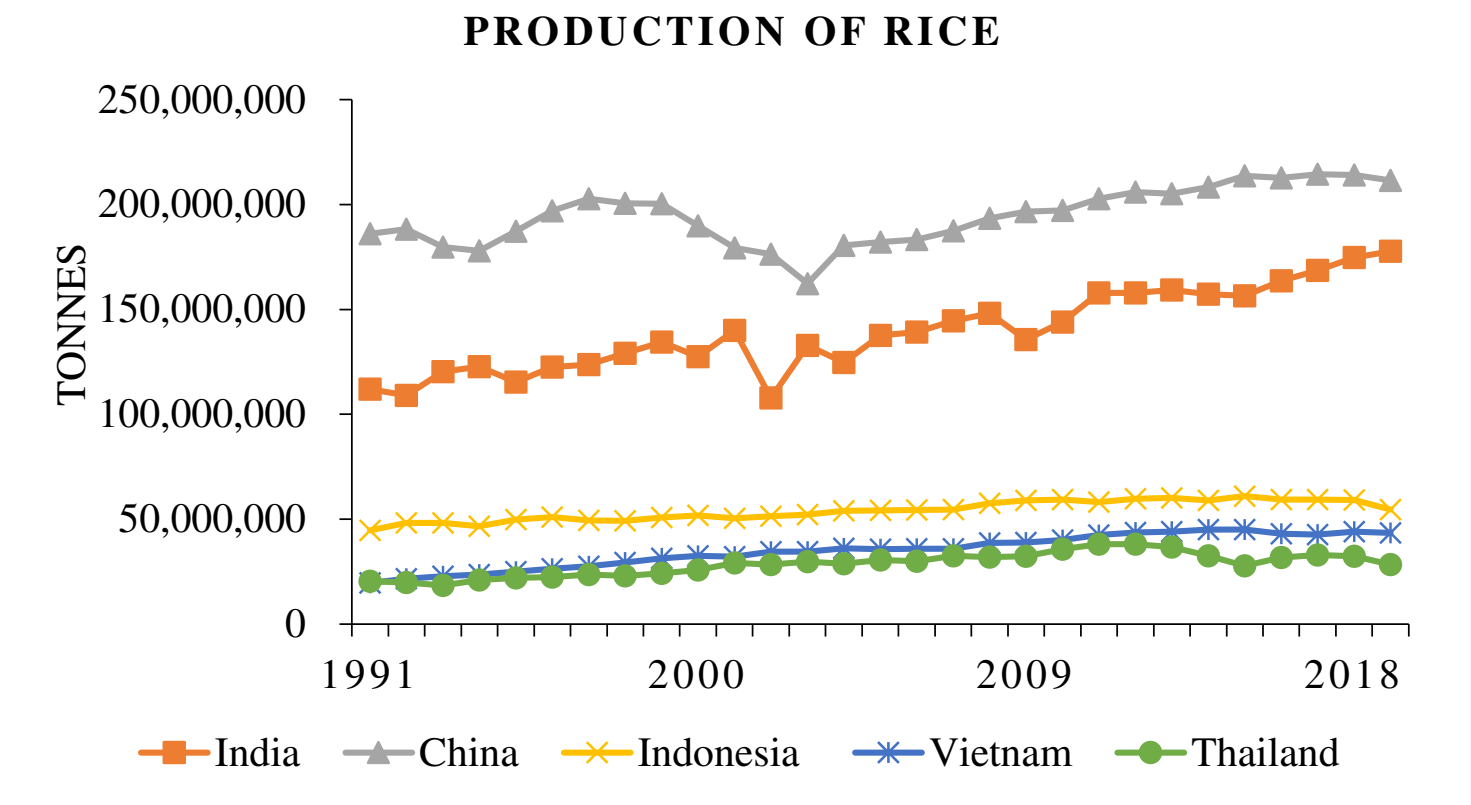

Figure 1: Trend of rice production in Asian countries

84 Sources: FAO 2019

Rice is one of India's main crops, which is largely shared area of cultivated land, i.e. 22.89 per cent in India. Apart from, it is the main staple crop of Asian countries and particularly in India, so the demand has increased from 93.99 million tonnes in 2012-13 to 108.16 in 2020-21 and demand projected in 2029-30 will be 117.56 million tonnes in India (Directorate of Economics and Statistics, 2019). Increasing rice production is needed to meet the demand for rice production in India and Asia. It largely depends on climate conditions and mainly grown in the rain-fed areas that received heavy rainfall in India. Climate and weather play a significant role in influencing rice productivity (Ahsan et al., 2020). Due to the deficiency of rainfall annual growth rate of rice production has a sharp decline of $10.1 \%$ in 2009-10 in India (see Figure 2).

\section{Annual Growth Rate}

\section{0}

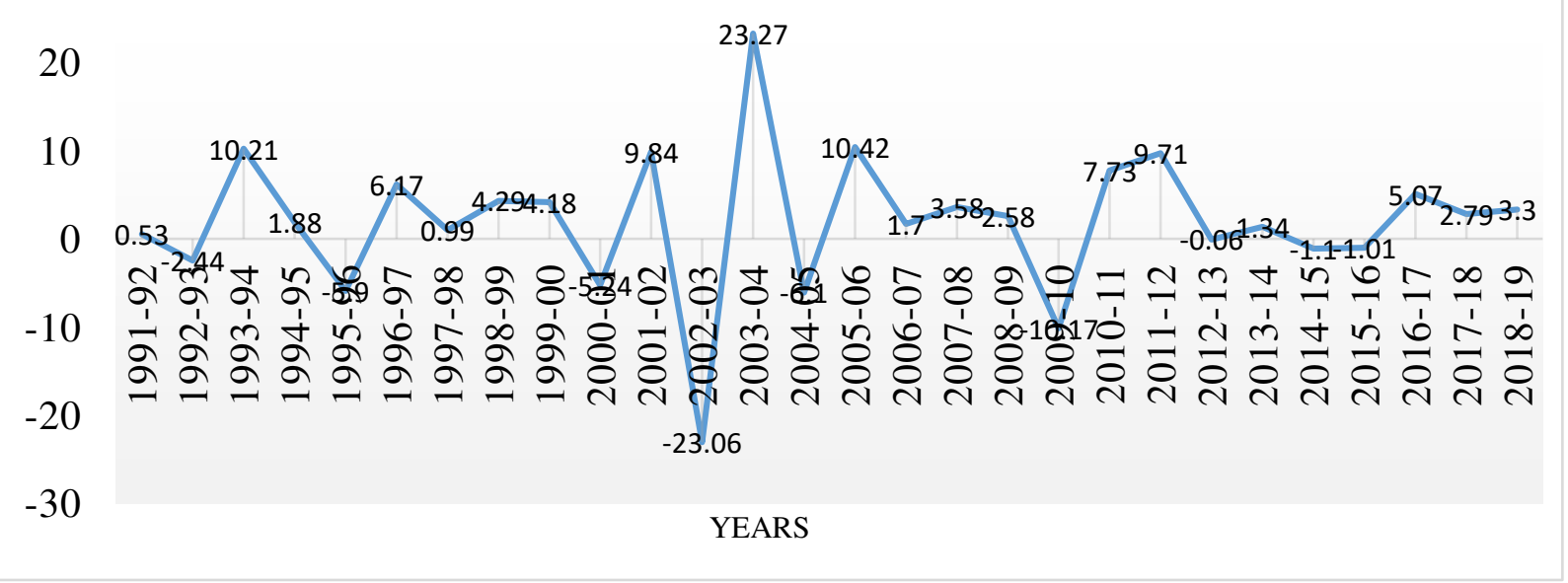


Sources: CMIE Commodities (2019)

96 The annual growth rate of rice has $1.01 \%$ in $2015-16,5.07 \%$ in $2016-17,2.79 \%$ in $2017-18$ and $3.3 \%$ in $2018-19$ in

97 India. This variation in the growth rate implies that growth depends on the nature of rainfall and temperature, which

98 is affected due to climate change in the tropics, the most susceptible region of the World. Mostly, rice currently

99 cultivated in those region where temperature already above optimal for production. However, any further increase in

100 temperature may be harmful to rice productivity during the sensitive period of the rice crop. Korres et al. (2017) stated

101 that in future India may be no longer suitable cultivator of rice production. Climate change has disastrous effect on

102 crop production as well as food security in developing economics (Sarker et al., 2019). Due to the complex interaction

103 between the yield of crop and climate change, it is the challenging assignment to tackle climate change and its impact

104 on agricultural productivity. Many previous studies have done by using various climate models over the Indian region

105 to examine the impact of increasing temperature and changing rainfall patterns during the twenty-first century (Bhatla

106 et al., 2019). However, this study's main objectives are to explore whether the dynamic relationship is symmetrical

107 and asymmetrical between rice productivity and climate change in India over the period 1990 to 2017 by using both

108 ARDL and NARDL approaches.

109 The rest of the paper is framed in the following manner. Section 2 discusses the existing literature and several

110 approaches to measure the impact of climate change on rice productivity. Section 3 mentions the data and

111 methodology. Empirical result and discussion are presented in section 4, and in the last section 5 provides the

112 conclusion and policy implication.

113 Related Literature Review

114 Numerous studies have been done on the relationship between climate change and agricultural productivity across the 115 globe, and there is growing consensus among environmentalist and researcher that the negative relationship exists 116 between the climate change and agriculture productivity in developing nations (Khanal et al., 2018). Among previous 117 studies conducted by Gupta \& Mishra (2019) at India level and Kumar et al. (2020) at states level, i.e. Uttar Pradesh 118 and Haryana respectively employ the Crop Simulation Model (CSM) and Ricardian regression approach to assess the 119 nature of the relationship between climate change and rice productivity. Gupta \& Mishra (2019) stated that multi-

120 Global Climate Model indicate that it expected to increase in productivity of rice most of the agro-ecological zones in 121 Representative Concentration Pathways (RCP) 2.6 but as on moving towards RCP 8.5 through RCP 4.5 and 6.0, the 122 positive impact on rice yield in RCP 2.6, in major rice-producing zones, is expected to mitigate and lead to the negative impact by 2080s. Large spatiotemporal variability is expected in most of the zones with enormous variability in arid and hilly zones. The overall change in spatial rice yield in India taking all used GCM-RCP combinations in consideration is expected to vary from $1.2 \%$ to $8.8 \%, 0.7 \%$ to $12.6 \%$, and $-2.9 \%$ to $17.8 \%$ due to the expected climate change in the 2020s, 2050s and 2080s, respectively. Whereas, Guiteras (2009) explained that major crop yield would harmfully be affected by 4.5 to $9 \%$ due to climate variation from 2010 to 2039 in India. In the same order, in the absence of adaptation productivity, the crop would reduce up to $25 \%$. Kumar et al. (2020) found that any large deviation in the rainfall harms rice and wheat production in Uttar Pradesh. In contrast, maximum temperature has a negative impact on rice and wheat in Uttar Pradesh and Haryana. While increasing temperature has a positive effect on rice production but negatively impact on grain. Abbas \& Mayo (2019) reported that maximum temperature has 
negative impact on rice plant in which decrease number of plants in plantation stage and minimum temperature has positively affected rice crop at replantation stage during vegetative phase. The rainfall has negative impact on rice crop during heading and flowering stage. Likewise (Auffhammer et al., 2012) point out that heavy rainfall and drought have a negative impact on rice yield in the rain fed areas during the 1966-2002 period, and lower rainfall and warmer night would not occur, then rice yield would increase by 4 per cent in India. In contrast (Rayamajhee et al., 2020) stated that there is no direct relationship between the rainfall and rice production in Nepal. Attiaoui \& Boufateh (2019) and Abbas (2020) find that linear long-run dynamic relationship between climate change and agriculture productivity. Empirical results reveal that deficiency of rainfall and high temperature respectively has negatively and positively affected agriculture productivity. Baig et al. (2020) also employ linear dynamic ARDL model to assess the impact of climate change on yield of major crops including rice, wheat, coarse cereals and pulse in India. Evidence of outcome indicated a linear long-run association between climate change and yield of the crop. However, annual mean temperature has a positive impact on the yield of wheat, coarse cereals and pulse except for rice while rainfall has a positive impact on rice, coarse cereals and pulse except for wheat in India. In contrast, Mitra (2014) and Pal \& Mitra (2018) investigated the nonlinear relationship between climate change and crop productivity in India. Mitra (2014) found no asymmetric relationship between rainfall and food grain in India and observed that average rainfall has a greater impact on food grain production than below-average rain. In contrast, Pal \& Mitra (2018) explain that coefficient of rainfall has a greater impact on the production of food grain up to $75^{\text {th }}$ quantile and reduce after that in India. While Nsabimana \& Habimana (2017) conducted a study in Rwanda's context, they stated that rainfall has an asymmetric impact on the price of crop in the short and long-run. Moreover, the price of food crop has gone down in the season of harvest, and after that, it has been increasing. Likewise (Moore et al., 2017) conducted a study to examine the impact of climate change on agricultural yield and welfare using database yield to systematically compare results from process-based and empirical studies. He stated that the asymmetric impact of climate change on welfare and agriculture yield, and showing the substantial probability of large declines in welfare for warming of $2{ }^{\circ} \mathrm{C}-3{ }^{\circ} \mathrm{C}$ even including the $\mathrm{CO} 2$ fertilization effect. Some previous studies (Belloumi, 2008; Fezzi \& Bateman, 2016; Kabubo-mariara \& Karanja, 2007) has observed non-linear relationship between climate change and revenue of agriculture crops. So it is a challenging task to cope with it due to the complex asymmetrical association between climate change and agriculture productivity. In this manner, the objective of this study is to answer of this question "whether the dynamic relationship between the rice productivity, and climate change is symmetrical or asymmetrical" in India. To the best of the author's knowledge, no studies have been done to assess both symmetrical and asymmetrical dynamic relationship between climate change and rice productivity using the ARDL and the NARDL cointegration approaches in the context of India. This study contribute in the existing literature in a such a manner, it reveals that climate factors affect the agriculture productivity in different magnitude, accordingly we need appropriate policy to cope detrimental effect of climate change on agriculture productivity.

166 Crop modelling, Ricardian and econometric approach, these are three approaches to measure the effect of climate change on agricultural productivity. Table 1 shows the history of literature in which researchers used above-mentioned methods to analyse the impact of climate change on agricultural productivity across the globe. 
Table 1: History of Previous Studies

\begin{tabular}{|c|c|c|}
\hline \multicolumn{3}{|c|}{ Crop Simulation/Modelling Method } \\
\hline $\begin{array}{l}\text { Author } \\
\text { Country }\end{array}$ & Variables & \\
\hline Gupta \& Mishra (2019) & Yield of rice, annual rainfall \& temperature & India \\
\hline (K. S. K. Kumar, 2011) & Yield of crop, rainfall, tractor \& area & India \\
\hline Kumar et al. (2011) & Yield of four major cereals & India \\
\hline (Lal et al., 1998) & Yield of rice and wheat $\&$ climate variables & India \\
\hline (Mishra \& Chandra, 2016) & Agriculture production, temperature and rainfall & Odisha(India) \\
\hline (Mukherjee \& S.Huda, 2018) & Yield of wheat, rainfall \& temperature & India \\
\hline (Auffhammer et al., 2012) & Yield of rice, mansoon and rainfall & India \\
\hline \multicolumn{3}{|c|}{ Linear Econometric Models } \\
\hline (Shujaat Abbas, 2020) & Cotton Production, Temperature, Area \& Fertilizer & Pakistan \\
\hline (Attiaoui \& Boufateh, 2019) & Production, labour, rainfall, \& temperature & Tunisia \\
\hline $\begin{array}{l}\text { (Baig et al., 2020) } \\
\text { (Bhanumurthy \& Kumar, } \\
\text { 2018) }\end{array}$ & $\begin{array}{l}\text { Yield of major crops, Temperature, rainfall, Co2 \& Fertilizer } \\
\text { Agriculture Output, Temperature, rainfall, GCF \& Irrigated } \\
\text { Area }\end{array}$ & India \\
\hline (Birthal et al., 2014) & Yield of the crop, Temperature rainfall \& Irrigation & India \\
\hline (Guntukula, 2020) & $\begin{array}{l}\text { Yield of major crops, Temperature \& rainfall } \\
\text { Yield of Wheat, Temperature, Precipitation, Area, Fertilizer \& }\end{array}$ & India \\
\hline Janjua et al. (2014) & $\mathrm{Co} 2$ & Pakistan \\
\hline Kumar et al. (2020) & $\begin{array}{l}\text { Yield of the crop, Rainfall, tractor, Area, literacy Rate \& Forest } \\
\text { Area } \\
\text { Yield of Rabi \& Kharif Crop, Area, Fertilizer, Tractor, Rainfall }\end{array}$ & $\begin{array}{l}\text { Haryana \& } \\
\text { U.P }\end{array}$ \\
\hline (A. Kumar et al., 2015) & $\begin{array}{l}\text { \& Temperature } \\
\text { Productivity of crop, rainfall, Temperature, Fertilizer and Area }\end{array}$ & India \\
\hline (H. K. Nath \& Mandal, 2018) & Sown & India \\
\hline (Praveen \& Sharma, 2020) & Yield of 15 Crops, mean temperature and rainfall & India \\
\hline (S. Gupta et al., 2012) & $\begin{array}{l}\text { Yield of rice and millets, Temperature, precipitation, irrigation } \\
\text { and labour }\end{array}$ & India \\
\hline \multicolumn{3}{|c|}{ Non Linear Model } \\
\hline (Mitra, 2014) & Yield of Major crop, Rainfall, fertiliser \& Pesticide & India \\
\hline 2017) & Yield of crops \& rainfall & Rwanda \\
\hline (Pal \& Mitra, 2018) & Agriculture production \& rainfall & India \\
\hline
\end{tabular}

Data and Methodology

171 Data

172 Time series data spanning from 1991 to 2017, has been collected from various sources. Table 2 shows the description

173 and sources of the data of variables viz. productivity of rice as a dependent variable, whereas mean temperatures in 174 Celsius degree, annual rainfall and area under cultivated land as explanatory variables. Descriptive statistics of 175 variables are reported in Table 3, which reveal that all the variables are normally distributed.

Table-2: Description of the variables

\begin{tabular}{llll}
\hline Variables & Notations & Description of Variables & Sources
\end{tabular}




\begin{tabular}{|c|c|c|c|c|c|c|}
\hline \multicolumn{2}{|c|}{ Productivity of rice } & & \multicolumn{2}{|c|}{$\mathrm{Kg} /$ hectares } & \multicolumn{2}{|c|}{$\begin{array}{l}\text { Directorate of Economics \& } \\
\text { Statistics }\end{array}$} \\
\hline \multicolumn{2}{|c|}{ Mean Temperature } & MTEMP & \multicolumn{2}{|c|}{ Degree Celsius (Centigrade) } & \multicolumn{2}{|c|}{$\begin{array}{l}\text { Meteorological Department of } \\
\text { India }\end{array}$} \\
\hline \multicolumn{2}{|l|}{ Rainfall } & $\mathrm{RF}$ & \multicolumn{2}{|c|}{$\begin{array}{l}\text { Annual average rainfall } \\
(\mathrm{mm})\end{array}$} & \multirow{2}{*}{\multicolumn{2}{|c|}{$\begin{array}{l}\text { Meteorological Department of } \\
\text { India } \\
\text { Directorate of Economics \& } \\
\text { Statistics }\end{array}$}} \\
\hline \multicolumn{2}{|c|}{$\begin{array}{l}\text { Area Under Cultivated } \\
\text { Land }\end{array}$} & AUR & \multicolumn{2}{|c|}{ Area cultivated land (hc) } & & \\
\hline \multicolumn{7}{|c|}{ Sources: Calculated by Authors } \\
\hline Variables & Mean & Median & S.D & Kurtosis & Skewness & J-B(Prob.) \\
\hline YR & 912.63 & 896.80 & 118.47 & -1.03 & 0.14 & 0.511 \\
\hline MTEMP & 25.61 & 25.68 & 1.72 & 4.48 & -0.31 & 0.648 \\
\hline RF & 1141.49 & 1133.00 & 92.37 & -0.72 & 0.05 & 0.690 \\
\hline AUR & 434.18 & 434.90 & 10.88 & 2.43 & -0.03 & 0.83 \\
\hline
\end{tabular}

Sources: Calculated by Authors

\section{ARDL Bound Cointegration Test}

178 Prior, to check the asymmetric dynamic relationship between climate change and rice productivity, we first employ

179 linear ARDL bound cointegration technique to analyse the linear dynamic relationship between climate change and rice productivity. There are some advantages of the ARDL model, the first advantage of this model; it is applicable in any situation either variable is integrated at ' 0 ' or ' 1 ' and at fractionally integrated. Second, the empirical results are unbiased and efficient, even if the sample size is small. A third important advantage of this model in choosing the appropriate number of lags for the empirical analysis. The dynamic long-run relationship is tested by computing the general F-statistics or Wald test statistics and comparing them with the two critical bounds values, i.e. lower and upper bound. If the value of F-statistics greater than the upper bound, means long-run linear relationship exist between the variables, if the value of F-statistics falls below the lower bound, the null hypothesis is not rejected, means no longrun association between the variables, and if the value falls within the lower and upper bound, results are inconclusive (Pesaran.et.al., 2001; Pesaran \& Shin, 2002).

NARDL Bound Test for Cointegration

Employing recently developed and advanced technique NARDL to assess the asymmetrical and non-linearity impact of temperature and rainfall on rice productivity. ARDL technique ignored the non-linearity and asymmetrical relationship among the variables. The ARDL model is expanded to an asymmetric ARDL or NARDL by Shin et al. (2014) to examine the pattern of dynamic adjustment and asymmetries relationship in the short and long-run between the variables. To explore the relationship between the variables following model can be specified as:

$$
Y_{t}=f\left(M T E M P_{t}, \text { Rainfall }_{t}, A U R_{t}\right)
$$


In the above equation, $\mathrm{Y}_{\mathrm{t}}$ indicates the productivity of rice in kilogram per hectare, and MTEMP indicates annual mean temperature, average annual rainfall and area under cultivated land. Equation.1 can also be written as:

$$
Y_{t}=\alpha_{0}+\alpha_{1} M T E M P_{t}+\alpha_{2} R A I N F A L L_{t}+\alpha_{3} A U R_{t}+\varepsilon_{t}
$$

General forms of long-run asymmetry relationship given as follows:

$$
Y_{t}=\beta^{+} X_{t}^{+}+\beta^{-} X_{t}^{-}+\varepsilon_{t}
$$

Where; $Y_{t}$ is a $k \times 1$ vector of rice productivity at time $t$; where $\beta^{+}$and $\beta^{-}$are the associated asymmetric long-run parameters. Here $X_{t}$ as $k \times 1$ vector of regressors is decomposed as:

$$
X_{t}=X_{0}+X_{t}^{+}+X_{t}^{-}
$$

The $X_{t}^{+}$and $X_{t}^{-}$are partial sum processes of positive (+) and negative (-) changes in $X t$ defined as:

$$
\begin{gathered}
X_{t}^{+}=\sum_{i=1}^{t} \Delta X_{i}^{+} ; \quad X_{t}^{-}=\sum_{i=1}^{t} \Delta X_{i}^{-} ; \\
\Delta X_{i}^{+}=\sum_{i=1}^{t} \max \left(\Delta X_{i,}, 0\right) ; \Delta X_{i}^{-}=\sum_{i=1}^{t} \min \left(\Delta X_{i,}, 0\right)
\end{gathered}
$$

Where; $\Delta X \mathrm{i}$ is the changes in independent variables $\left(X_{t}\right)$ while the superscript '+' and '-' represents the positive and negative processes around a threshold of zero, which delineates positive and negative shocks in the explanatory variables, this implies that the first differenced series is assumed to be normally distributed with zero means.

Shin, Yu and Greenwood-Nimmo (2014) prolong the ARDL model adopted by the Peasaran et al. (2001) by utilising the concept of cumulative positive and negative partials sums. In this manner, the NARDL (p, q) model is given below:

$$
Y_{t}=\sum_{i=1}^{p} \beta_{i} Y_{t-1}+\sum_{i=1}^{q}\left(\gamma_{i}^{+} X_{t-I}^{+}+\gamma_{i}^{-} X_{t-1}^{-}\right)+\varepsilon_{t}
$$

Where; $Y_{t}$ is $\mathrm{k} \times 1$ is a vector of multiple regressors; $\beta_{i}$ is the autoregressive parameter; $\gamma_{i}^{+}$and $\gamma_{i}^{-}$are the asymmetrically distributed lag parameters while $\varepsilon_{t}$ is the error term which is assumed to be normally distributed. Following Shin et al. (2014), the modified error correction form is specified as:

$$
\begin{gathered}
\Delta Y_{t}=\rho Y_{t-1}+\alpha^{+} X_{t-1}^{+}+\alpha^{-} X_{t-1}^{-}+\sum_{i=1}^{p} \beta_{i} Y_{t-i}+\sum_{i=1}^{q}\left(\gamma_{i}^{+} \Delta X_{t-i}^{+}+\gamma_{i}^{-} \Delta X_{t-i}^{-}\right)+\varepsilon_{t} \\
\Delta Y_{t}=\rho E c t_{t-1}+\sum_{i=1}^{p} \beta_{i} Y_{t-1}+\sum_{i=1}^{q}\left(\gamma_{i}^{+} \Delta X_{t-i}^{+}+\gamma_{i}^{-} \Delta X_{t-i}^{-}\right)+\varepsilon_{t}
\end{gathered}
$$

In the above equation, $E c t_{t-1}=Y_{t}-\beta^{+} X_{t}^{+}-\beta^{-} X_{t}^{-}$is the asymmetrical error correction term and $\beta_{X}^{+}=-\alpha^{+} / \rho$ and $\beta_{X}^{-}=-\alpha^{-} / \rho$ is associated with the asymmetric long-run parameters. Estimation procedure of the NARDL is same as linear ARDL. The null hypothesis of asymmetrical long-run relationship, $\rho=\alpha^{+}=\alpha^{-}=0$ between the variables. Null hypotheses have been tested by computing the general F-statistics or Wald test statistics and by comparing them with the two critical bounds values (lower and upper bound), that provide a band covering all possible classifications of the regressors into purely $I(0), I(1)$ or mutually cointegrated. The long-run $\left(\alpha^{+}=\alpha^{-}\right)$and short- 
run $\left(\gamma_{i}^{+}=\gamma_{i}^{-}\right)$asymmetries estimates through the Wald test. The long-run and short-run asymmetries will also be estimated using the standard Wald test.

226 These short and long-run asymmetry paths can respectively be presented relying on the cumulative dynamic multiplier effect a unit percentage change in $X_{t}^{+}$and $X_{t}^{-}$on $Y_{t}$ obtain through the following equation:

$$
m_{h}^{+}=\sum_{i=0}^{h} \frac{\partial Y_{t+i}}{\partial X_{t}^{+}} ; \quad m_{h}^{-}=\sum_{i=0}^{h} \frac{\partial Y_{t+i}}{\partial X_{t}^{-}} ; \quad \mathrm{h}=0,1,2 \ldots \ldots \ldots \ldots .
$$

$$
\text { Noting that, } \mathrm{h} \rightarrow \infty, m_{h}^{+} \rightarrow \beta^{+} \text {and } m_{h}^{-} \rightarrow \beta^{-}
$$

230 Thus the NARDL model for underlying variables as follows:

$$
\begin{aligned}
\Delta \text { lnYield }_{t}=\alpha_{0}+ & \text { slnYield }_{t-1}+\alpha_{1}^{+} \text {Meantem }_{t-1}^{+}+\alpha_{1}^{-} \text {Meantemp }_{t-1}^{-}+\alpha_{2}^{+} \text {Rainfall }_{t-1}^{+}+\alpha_{2}^{+} \text {Rainfall }_{t-1}^{-} \\
& +\alpha_{3}^{+} \text {AUR }_{t-1}^{+}+\alpha_{3}^{+} \text {AUR }_{t-1}^{-}+\sum_{i=1}^{p} \beta_{i} \Delta Y_{t-i}+\sum_{j=1}^{j=p}\left(\theta_{j}^{+} \Delta \text { Meantemp }_{t-1}^{+}+\theta_{j}^{-} \Delta \text { Meantemp }_{t-1}^{-}\right) \\
& +\sum_{j=1}^{j=p}\left(\gamma_{j}^{+} \Delta \text { Rainfall }_{t-1}^{+}+\gamma_{j}^{-} \Delta \text { Rainfall }_{t-1}^{-}\right)+\sum_{j=1}^{j=p}\left(\vartheta_{j}^{+} \Delta A U R_{t-1}^{+}+\vartheta_{j}^{-} \Delta A U R_{t-1}^{-}\right)+\delta E C T_{(-1)} \\
& +U_{t}
\end{aligned}
$$

Where; $\mathrm{p}$ and $\mathrm{q}$ are representing lags order of dependent and independent variables, respectively. Meantemp ${ }^{+}$, Meantemp', Rainfall ${ }^{+}$, Rainfall- and $\mathrm{AUR}^{+}$, AUR ${ }^{-}$respectively indicate the partial sum of positive (+) and negative () changes in the annual mean temperature, annual average rainfall and area under cultivated land. Akaike and Schwarz information criteria have been used to find out the optimal lag selection in the model. $E C T_{-1}$ is the error correction term, and $\delta$ is the speed of adjustment in the process to restore equilibrium following a disturbance in the asymmetrical long-run equilibrium relationship. The adequacy and stability of the specified NARDL models are also checked with various Diagnostic tests.

\section{Empirical Results and Discussions}

243 Stationarity: Prior to applying the NARDL, we check the order of integration because NARDL model does not give efficient and appropriate results in case of variables are integrated of order 2. The Dicky-fuller and Philips-Perron unit root tests are employed to check the stationarity of all the variables. The results of the stationarity of underlying

246 variables shown in Table 4.

247 Table 4. Unit Root Tests

\begin{tabular}{ccccc}
\hline & \multicolumn{2}{c}{$\mathrm{I}(0)$} & $\mathrm{I}(1)$ & $\mathrm{PP}$ \\
\cline { 2 - 5 } Variables & $\mathrm{ADF}$ & $\mathrm{PP}$ & $-9.54 * * *$ & $-13.46^{* * *}$ \\
YR & $-4.99 * * *$ & $-5.01 * * *$ & $-5.95 * * *$ & $-9.46 * * *$ \\
MTEMP & $-6.29 * * *$ & $-5.57 * * *$ & $-8.55 * * *$ & $-24.55 * * *$ \\
Rainfall & $-5.54 * * *$ & $-5.64 * * *$ & $-7.73 * * *$ & $-7.81 * * *$ \\
AUR & $-4.07 * * *$ & $-3.74 * * *$ &
\end{tabular}

Source: Calculated by Authors Notes: '*', "**", and "***" denote the 10\%, 5\%, and 1\% level of significance respectively. 
Table 4 reveals that all the variables are stationary at levels. Results explain that productivity of rice, mean temperature, rainfall and area under cultivated land are stationary at $1 \%$ level of significance. None of the variables is integrated of order 2 in this study that corroborates NARDL bound testing.

251 The commonly unit root tests such as Augmented and Dicky-Fuller and Phillips and Peron test does not capture the 252 break in the series. However, Zivot and Andrews structural break unit root test has been applied to overcome this 253 problem. Table 5 present result of a structural break unit root test and indicate that underlying variables are stationarity 254 with the different break in the series. Due to the drought in 2002 in India, agricultural productivity had been sharply gone down (Gulati et al., 2013). Hence the structural break has arisen in the data of rice productivity. Due to the presence of the structural breaks in the data, the variables may have non-linearity. Hence to check non-linearity, we employ BDS independence test, as it checks whether there is any presence of linear dependence in the dependent variable in the model.

Table 5, Zivot \& Andrews (1992) Structural Break Unit root Test

\begin{tabular}{ccc}
\hline Break-in Intercept and trend & \multicolumn{2}{c}{ At Level } \\
\cline { 2 - 3 } Variables & T-statistics & Break \\
\hline YR & $-8.06^{* * * *}$ & 2002 \\
MTEMP & $-10.27^{* * * *}$ & 2002 \\
Rainfall & $-6.67^{* * *}$ & 2000 \\
AUR & $-7.79^{* * *}$ & 2008 \\
\hline
\end{tabular}

Source: Calculated by Authors Notes: '*', "**", and "***" denote the 10\%, 5\%, and 1\% level of significance respectively.

259 Table 6 depicts the result of the non-linearity of the underlying variables. At the $1 \%$ level, BDS statistics reject the 260 null hypothesis of residual of being independent and identically distributed at all the dimension, which indicates that 261 non-linearity in the dependent variable, i.e. rice productivity. Apart from, non-linearity also exists in the area under cultivated land, annual mean temperature and annual rainfall.

Table 6; BDS Test for Asymmetry or non-linearity

\begin{tabular}{cccccc}
\hline & \multicolumn{5}{c}{ Dimensions } \\
\cline { 2 - 5 } Variables & $\mathrm{m}=2$ & $\mathrm{~m}=3$ & $\mathrm{~m}=4$ & $\mathrm{~m}=5$ & $\mathrm{~m}=6$ \\
YR & $0.07 * * *$ & $0.13 * * *$ & $0.18 * * *$ & $0.18^{* * *}$ & $0.16^{* * * *}$ \\
MTEMP & 0.01 & $0.09 * *$ & $0.19 * * *$ & $0.25 * * *$ & $0.28 * * *$ \\
Rainfall & -0.01 & $-0.03 * *$ & $-0.08 * * *$ & $-0.07 * * *$ & $-0.07 * * *$ \\
AUR & $0.03 * * *$ & $0.08 * * *$ & $0.10 * * *$ & $0.11 * * *$ & $0.09 * * *$ \\
\hline
\end{tabular}

Sources: Calculated by Author, $* * *, * * \& *$ represent $1,5 \& 10 \%$ level of Significance

After confirming both structural breaks and asymmetry in the time series data, in this order, it is best to use the NARDL model to investigate the short and long-run asymmetrical relationship among the variables in this study. But first, we check the linear dynamic long-run association through ARDL bound cointegration model. The results are shown in Table 7 depicts the result of long-run bound cointegration approach between rice productivity, annual temperature,

267 average rainfall and area under cultivated land at the different lags order. F-statistics equal to 2.53, which is less than 
268 lower bound value, i.e. 4.29 at the $1 \%$ level of significance, which indicates no long-run linear relationships between 269 rice productivity and climate change. Thus, linear specification gives the spurious results due to the asymmetry in the 270 series or model. Thus we proceed to examine asymmetrical dynamic relationship amongst the variables.

Table 7. Results of the ARDL Bound Test

\begin{tabular}{cccc}
\hline & \multicolumn{3}{c}{ Long run Results } \\
\hline Variables & Coefficient & Std. Error & P-value \\
Meantemp & 13.53 & 7.96 & 0.11 \\
Rainfall & -0.44 & 0.18 & 0.02 \\
AUR & -0.76 & 1.09 & 0.49 \\
C & 624.92 & 450.25 & 0.18 \\
\hline & & Short Run Results & \\
Rice & -0.55 & 0.16 & 0.00 \\
Meantemp & 3.87 & 3.75 & 0.32 \\
Rainfall & 0.05 & 0.09 & 0.59 \\
AUR & 4.16 & 0.53 & 0.00 \\
& & & \\
\hline & Signif. & $\mathrm{I}(0)$ & 3.77 \\
F-Statistic= 2.53 & $10 \%$ & 2.72 & 4.35 \\
& $5 \%$ & 3.23 & 4.89 \\
& $2.5 \%$ & 3.69 & 5.61 \\
\hline
\end{tabular}

Sources: Calculated by Authors

271

\section{Results of NARDL Bound Test for Cointegration}

273 To choose the maximum lag, we applied the general to a specific technique. Maximum lag of dependent and 274 explanatory variables are $2(\mathrm{p}=\mathrm{q}=2)$ choose by the Akaike and Schwarz information criteria. Table 8 shows the results 275 of the asymmetrical relationship between the variables.

Table 8: The long results of NARDL ( Productivity of Rice is as dependent variable)

\begin{tabular}{|c|c|c|c|}
\hline Variables & Coefficient & Std. Error & Prob. \\
\hline Meantemp $^{+}$ & -8.09 & 4.52 & 0.09 \\
\hline Meantemp & -9.07 & 7.13 & 0.22 \\
\hline Rainfall $^{+}$ & 0.24 & 0.11 & 0.06 \\
\hline Rainfall- & -0.45 & 0.13 & 0.00 \\
\hline $\mathrm{AUR}^{+}$ & 3.72 & 1.02 & 0.00 \\
\hline AUR $^{-}$ & 3.47 & 0.62 & 0.00 \\
\hline Constant & 926.48 & 136.60 & 0.00 \\
\hline \multicolumn{4}{|c|}{ Bound Test: F-statistics $=17.68^{*}$} \\
\hline \multicolumn{2}{|c|}{ Level of Significance } & \multicolumn{2}{|c|}{ Critical Bound Values } \\
\hline & & $\mathrm{I}(0)$ & $\mathrm{I}(1)$ \\
\hline \multicolumn{2}{|c|}{$10 \%$} & 2.12 & 3.23 \\
\hline \multicolumn{2}{|c|}{$5 \%$} & 2.45 & 3.61 \\
\hline \multicolumn{2}{|c|}{$2.50 \%$} & 2.75 & 3.99 \\
\hline \multicolumn{2}{|c|}{$1 \%$} & 3.15 & 4.43 \\
\hline
\end{tabular}


Sources: Calculated by Authors, Notes: $(*)$ indicates $1 \%$ level of significance

276 Table 8 depicts the asymmetrical long-run results, which infers that annual mean temperature, rainfall and area under

277 cultivated land are composed of each two possible components, i.e. positive (+) and negative (-). Positive (+) and

278 negative (-) component of annual mean temperature has a negative effect on the productivity of rice, but the negative

279 component has insignificant in India. Impact of positive and negative shocks of temperature on rice productivity has

280 contributed by different magnitude. However, increase 1 degree Celsius in temperature, which leads to a decrease in

281 rice productivity by 8.09 unit. Similarly, decrease 1 degree Celsius in temperature has negatively affected rice

282 productivity by 9.07 unit. This outcome is in line with Abbas \& Mayo (2020), Chandio, Jiang, et al. (2020) and

283 Swaminathan \& Kesavan (2012) and their studies explained that temperature has negatively affected rice productivity.

284 Korres et al. (2017) revealed that negative relationship between rice yield and increased mean temperature, however

285 increased in mean temperature has negatively affected the rice yield. Furthermore, positive rainfall component has a

286 positive and significant impact on the rice productivity at the $5 \%$ level of significance and this outcome supported by

287 Rashid et al. (2012); Baig et al. (2020); Chandio, Jiang, et al., (2020) and Chandio, Ozturk, et al. (2020) and their

288 studies concluded that rainfall has a positive impact on agriculture productivity. Likewise, this result contradicts the

289 Arora et al. (2012), and Guntukula (2019) and their studies concluded that rainfall has a negative impact on rice

290 productivity in India. The negative component of rainfall has negatively affected rice productivity by 0.45 unit in

291 India. The negative component has a stronger effect than a positive component of rainfall on rice productivity;

292 however, deficiency of rainfall has more harmful to rice productivity because it largely depends on monsoon in India.

293 Moreover, positive and negative component of area under cultivated land respectively has positively affected rice

294 productivity by 3.72 and 3.47 units. Positive component of area under cultivated land has a larger magnitude than the

295 negative component to the rice productivity in India. The value of nonlinear F-statistics is 17.62 which is greater than

296 the upper critical bound value (5.06) at the $1 \%$ level of significance which reject the null hypothesis of "no

297 cointegration" clearly indicate that long-run asymmetric relationship exists between the variables.

Table 9: Short-run results of NARDL ( Productivity Rice is as dependent variable)

\begin{tabular}{cccc}
\hline Variables & Coefficient & Std. Error & Prob. \\
\hline Y & -0.45 & 0.12 & 0.00 \\
Rainfall $^{+}$ & 0.21 & 0.09 & 0.04 \\
Rainfall $^{-}$ & 0.55 & 0.15 & 0.00 \\
AUR $^{+}$ & 3.72 & 0.64 & 0.00 \\
ECT(-1) $^{2}$ & -1.21 & 0.09 & 0.00 \\
\hline $\mathrm{R}^{2}=0.87$, Adj. $\mathrm{R}^{2}=0.83$ \& D-W statistics=2.21 & & & \\
\hline
\end{tabular}

Sources: Calculated by Authors

Table 9 represents the results of the asymmetrical short-run impact on rice productivity. The results infer that the positive and negative component of rainfall has a positive impact on rice productivity. This outcome is similar to Birthal et al. (2014); Rashid et al. (2012) and Baig et al. (2020) and they concluded that rainfall has a positive impact on rice productivity. Similarly, Arora et al. (2012) contradicted this outcome and stated that rainfall negatively impacts rice productivity in India. Moreover, the positive component of the area under cultivated land has a positive and significant impact on rice productivity in the short run. The coefficients of error correction term (ECT) have inferred 
that rice productivity has adjusted its equilibrium with speed by $121 \%$ per year in the presence of annual temperature, rainfall and area under cultivated land in India.

Table 10: Results of the Wald Test

\begin{tabular}{ccccc} 
Explanatory Variables & \multicolumn{2}{c}{ Long-run Asymmetric } & \multicolumn{2}{c}{ Short-run Asymmetric } \\
\cline { 2 - 5 } & F-Statistics & P-value & F-Statistics & P-value \\
Rainfall & 7.79 & 0.01 & 9.98 & 0.00 \\
\hline Meantemp & 17.19 & 0.00 & - & - \\
\hline AUR & 0.03 & 0.84 & - & - \\
\hline
\end{tabular}

Sources: Calculated by the Authors

Table 10 depicts the result of short and long-run asymmetry. The P-value of Wald test rejects the null hypothesis of a long-run symmetrical relationship between annual mean temperature, rainfall, and rice productivity, which clearly indicate that long-run asymmetries in the positive and negative component of annual mean temperature and rainfall on rice productivity. Furthermore, the result also infers that there is the asymmetrical association between rice productivity and rainfall in the short-run in India. This result is supported by the Nsabimana \& Habimana (2017), which explained that rainfall has an asymmetric impact on agriculture productivity, and deficiency of rainfall has negatively affected agriculture yields and its revenue. Apart from, Mitra (2014) contradicted this result and concluded that no asymmetrical relationship between rainfall and food grain production. In contrast, P-value of area under cultivated land revealed that there is no asymmetrical relationship between rice productivity and area under cultivated land. Table 11 shows various diagnostic results such as heteroscedasticity, serial correlation, normality, and Ramsey RESET Test. P-value indicates there is no problem in the model, and data is normally distributed.

Table 11: Results of Diagnostic Tests

\begin{tabular}{lll} 
Diagnostic Test & Statistics & P-value \\
LM Test & 0.36 & 0.70 \\
roskedasticity Test & 0.87 & 0.58 \\
arque-Bera Test & 0.82 & 0.66 \\
msey RESET Test & 0.54 & 0.47 \\
\hline
\end{tabular}

Sources: Calculated by the Authors

The figure, 3 indicates the result of CUSUM and CUSUMQ to assess the stability of parameters at the $5 \%$ level of significance. The blue line shows the estimated line, which is lies within the two critical red lines which indicate that parameters are stable in this model at the $5 \%$ level of significance. 

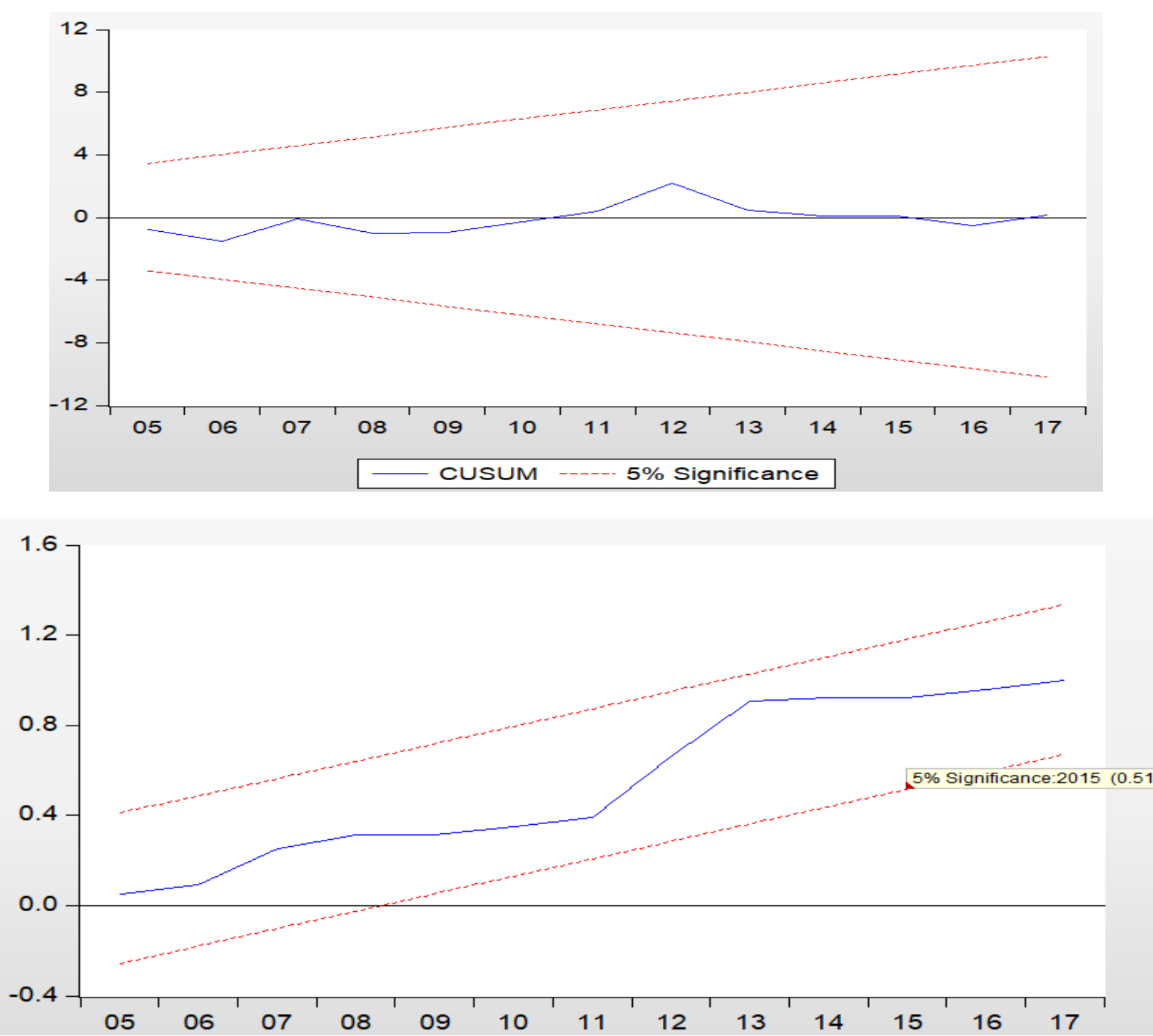

Figure 3: CUSUM and CUSUMQ square

Figure $4(\mathrm{a}, \mathrm{b} \& \mathrm{c})$, depict the cumulative adjustment pattern of the rice productivity to a unitary negative (-) and positive $(+)$ component in annual rainfall, temperature and area under cultivated land. The negative (Black Dashed line) and positive (Continuous Blackline) line respectively measure cumulative adjustment of climate variables spread to negative and positive shocks at the given forecast horizon. The dark dotted red line is the asymmetry curve reflects the difference between the positive and negative shock of a dynamic multiplier of each independent variables. This asymmetry curve lies between line upper and lowers dotted two red lines in order to provide the measures of asymmetry at a given horizon at the $95 \%$ level of significance. 


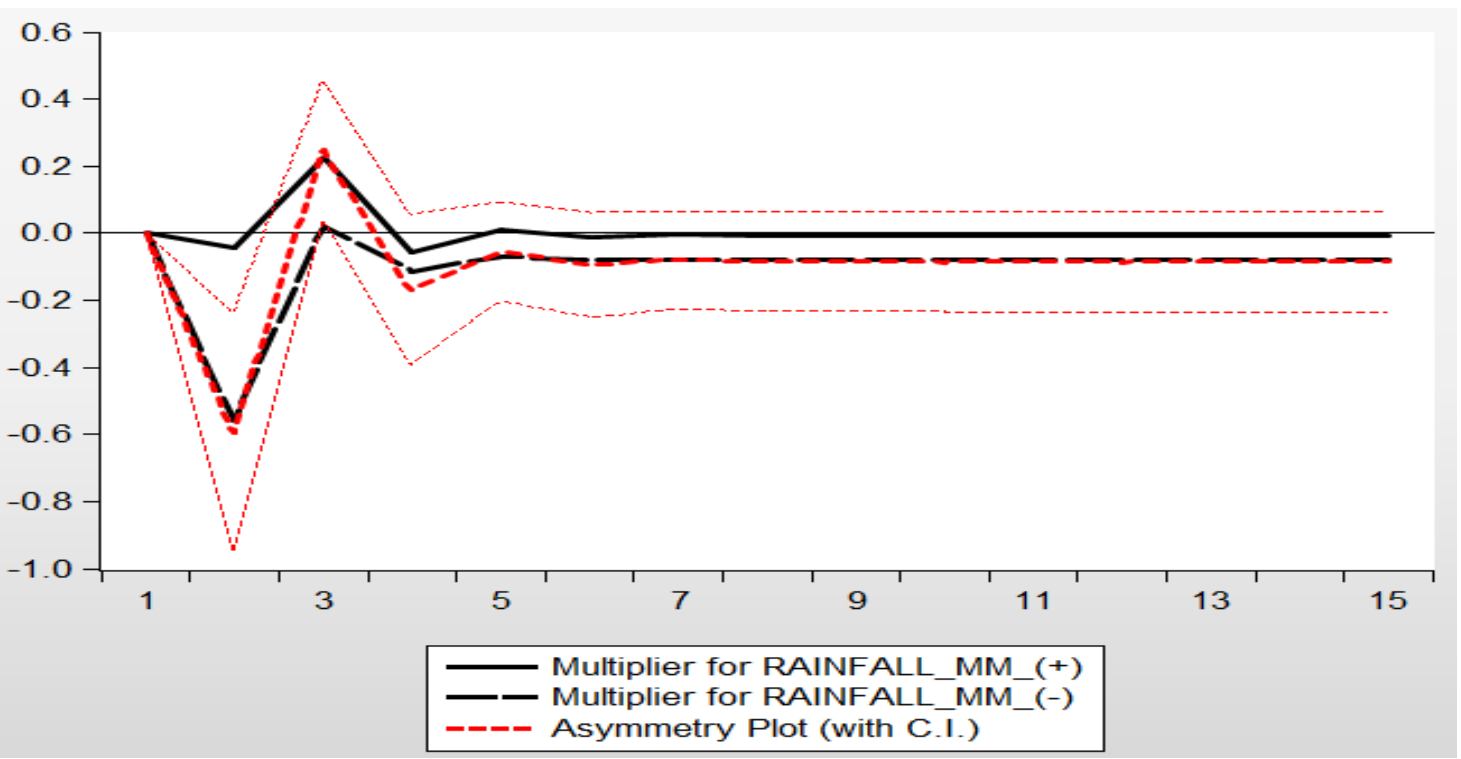

Figure 4 (a): Result of Dynamic Multiplier Graph

Figure 4 (a) indicates that the Positive and negative component of annual rainfall has a positive and negative shock in rice productivity, respectively. The negative component has a dominant shock over the positive component of rainfall in rice productivity.

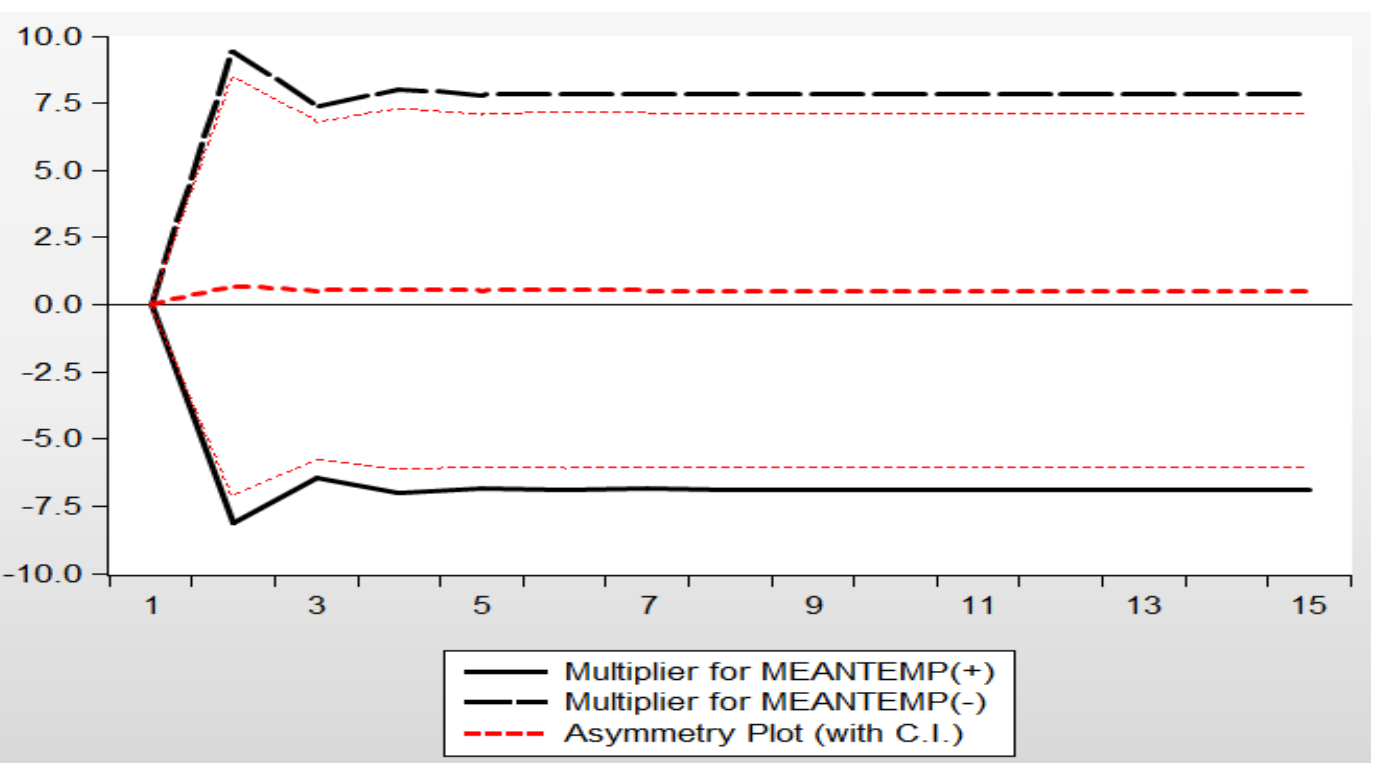

Figure 4 (b): Result of Dynamic Multiplier Graph

While, Figure 4 (b), infer that long-run asymmetry in the rice productivity due to changes of positive and negative shock in mean temperature, the negative component has dominant shocks over the positive component on the rice productivity. 


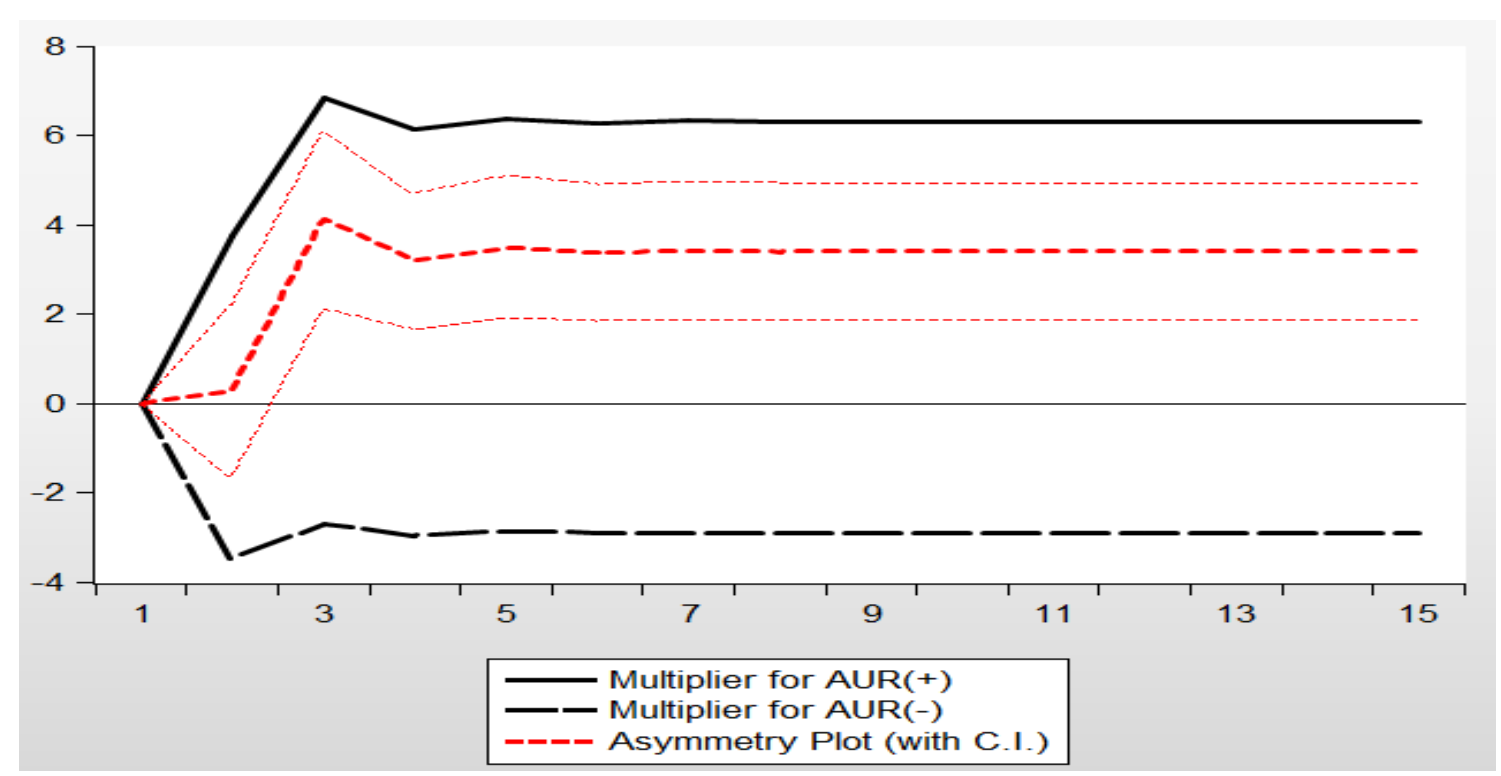

Figure 4 (C): Result of Dynamic Multiplier Graph

Furthermore, Figure 4 (c) revealed that positive component of area under cultivated land has dominant shock over the negative shock on the rice productivity in India.

\section{Concluding Remarks and Policy Implications}

This paper examines whether the dynamic relationship is symmetrical and asymmetrical between climate change and rice productivity using linear ARDL and NARDL cointegration approach during 1990-2017 in India. NARDL techniques developed by Shin et al. ( 2014), which is the extension model of linear ARDL, captures the asymmetries relationship between the variables both in the long and short-run and provides an efficient and flexible approach that transmission of positive and negative shocks in each explanatory variables to the rice productivity.

The empirical outcome of ARDL infers that the absence of a linear dynamic relationship between climate change and rice productivity in India. Whereas, NARDL result indicates a significant long-run and dynamic asymmetric relationship between climate change and rice productivity in India. The positive and negative shock of climate change has affected the rice productivity by different magnitude in India. However, the linear ARDL model has not appropriate to effectively measure the asymmetries impact of climate change on rice productivity in the short and long-run and might lead to misspecified and biased results. In particular, asymmetric long-run result, positive (+) and negative (-) annual mean temperature component negatively affect rice productivity in India. In contrast, positive and negative component of rainfall respectively has a positive and negative impact on rice productivity. Moreover, the short-run positive and negative component of rainfall has a significant positive impact on rice productivity. Similarly, the positive component of the area under cultivated land has a positive impact on India's rice productivity.

This study's outcomes may be vital for planning and strategy for policymakers to adopt appropriate environmental policies and modern technology regarding precise climate forecasting, and precautionary and direct actions are also expected to create and support an improved water system framework. In a nutshell, crop-specific research should be conducted to highlight environmental problems. The Government should also take the initiative to cope with climate change's harmful effects on agriculture's productivity. The Government should provide better irrigation facilities such 
as water canal, tube wells, and government can subsidise the electricity to cope with deficiency of rainfall, enhancing rice production in India. To cope with climate change, the Government should set-up a team of two or three people to give guidance and proper knowledge regarding the different aspects of climate change phenomenon at the block level in India.

\section{Declaration:}

Ethics approval and consent to participate: Not applicable

Consent for publication: Not applicable

Availability of data \& Materials: Data will be made available upon request

Competing interests: The authors declare no competing interests.

Funding: Not applicable

Author's Contribution: Imran Ali Baig: Formal analysis, Methodology, Writing-Original draft. Abbas Ali Chandio: Writing- review \& editing. M.A. Salam : read and approved manuscript

\section{Reference:}

Abbas, Shujaat. (2020). Climate change and cotton production : an empirical investigation of Pakistan. Environmental Science and Pollution Research, 1998.

Abbas, Sohail, \& Mayo, Z. A. (2020). Impact of temperature and rainfall on rice production in Punjab, Pakistan. Environment, Development and Sustainability. https://doi.org/10.1007/s10668-020-00647-8

Ahmad, D., Chani, M. I., \& Humayon, A. A. (2017). Major Crops Forecasting Area, Production and Yield Evidence from Agriculture Sector of Pakistan. Sarhad Journal of Agriculture, 33(3), 385-396. https://doi.org/10.17582/journal.sja/2017/33.3.385.396

Ahsan, F., Chandio, A. A., \& Fang, W. (2020). Climate change impacts on cereal crops production in Pakistan: Evidence from cointegration analysis. International Journal of Climate Change Strategies and Management, 12(2), 257-269. https://doi.org/10.1108/IJCCSM-04-2019-0020

Artner, A. (2010). Micro-level Practices to Adapt to Climate Change for African Small-scale Farmers (No. 00953; Issue February).

Attiaoui, I., \& Boufateh, T. (2019). Impacts of climate change on cereal farming in Tunisia : a panel ARDL - PMG approach. Environmental Science and Pollution Research, 26(January 2011), 13334-13345.

Auffhammer, M., Ramanathan, V., \& Vincent, J. R. (2012). Climate change, the monsoon, and rice yield in India. Climatic Change, 111(2), 411-424. https://doi.org/10.1007/s10584-011-0208-4

Bahl, P. N. (2015). Climate Change and Pulses: Approaches to Combat Its Impact. Agricultural Research, 4(2), 103-108. https://doi.org/10.1007/s40003-015-0163-9 
Baig, I. A., Ahmed, F., Salam, A., \& Khan, S. M. (2020). An assessment of Climate change and Crop Productivity in India: A Multivariate Cointegration Framework. TEST Engineering \& Management, 83, 3438-3452.

Belloumi, M. (2008). The relationship between Trade , FDI and Economic growth in Tunisia: An application of autoregressive distributed lag model. 1-22.

Bhanumurthy, K. ., \& Kumar, L. (2018). Climate Change and Agriculture in India: Studying Long-Term Patterns in Temperature , Rainfall and Agriculture Ouput. Management and Economics Research Journal, 4(S2), 156173.

Bhatla, R., Ghosh, S., Verma, S., Mall, R. K., \& Gharde, G. R. (2019). Variability of Monsoon Over Homogeneous Regions of India Using Regional Climate Model and Impact on Crop Production. Agricultural Research, 8(3), 331-346. https://doi.org/10.1007/s40003-018-0368-9

Birthal, P. S., Khan, T., Negi, D. S., \& Agarwal, S. (2014). Impact of Climate Change on Yields of Major Food Crops in India : Implications for Food Security. 27(2), 145-155. https://doi.org/10.5958/09740279.2014.00019.6

Chandio, A. A., Jiang, Y., Akram, W., Adeel, S., Irfan, M., \& Jan, I. (2021). Addressing the effect of climate change in the framework of financial and technological development on cereal production in Pakistan. Journal of Cleaner Production, 288, 125637. https://doi.org/10.1016/j.jclepro.2020.125637

Chandio, A. A., Jiang, Y., Rehman, A., \& Rauf, A. (2020). Short and long-run impacts of climate change on agriculture: an empirical evidence from China. International Journal of Climate Change Strategies and Management, 12(2), 201-221. https://doi.org/10.1108/IJCCSM-05-2019-0026

Chandio, A. A., Ozturk, I., Akram, W., Ahmad, F., \& Mirani, A. . (2020). Empirical analysis of climate change factors affecting cereal yield : evidence from Turkey. Environmental Science and Pollution Research, 27, 11944-11957.

Chavas, D. R., Ce, R., Thomson, A. M., \& Gao, X. (2009). Long-term climate change impacts on agricultural productivity in eastern China. Agricultural and Forest Meteorology, 149, 1118-1128. https://doi.org/10.1016/j.agrformet.2009.02.001

Fezzi, C., \& Bateman, I. (2016). The Impact of Climate Change on Agriculture: Nonlinear Effects and Aggregation Bias in Ricardian Models of Farmland Values. Journal of the Association of Environmental and Resource Economists, 2(1), 57-92.

Guiteras, R. (2009). The Impact of Climate Change on Indian Agriculture (Issue September).

Gulati, A., Saini, S., \& Jain, S. (2013). Monsoon 2013 : Estimating the Impact on Agriculture. In Wmo (No. 269; Issue 269). https://doi.org/ISBN 978-92-63-11091-6

Guntukula, R. (2019). Assessing the impact of climate change on Indian agriculture : Evidence from major crop 
yields. Journal of Public Affairs, October, 1-7. https://doi.org/10.1002/pa.2040

442

443

444

445

446

447

448

449

450

451

452

453

454

455

456

457

458

459

460

461

462

463

464

465

466

467

468

469

470

471

Guntukula, R. (2020). Assessing the impact of climate change on Indian agriculture: Evidence from major crop yields. Journal of Public Affairs, 20(1), 1-7. https://doi.org/10.1002/pa.2040

Gupta, R., \& Mishra, A. (2019). Climate change induced impact and uncertainty of rice yield of agro-ecological zones of India. Agricultural Systems, 173(February), 1-11. https://doi.org/10.1016/j.agsy.2019.01.009

Gupta, S., Sen, P., \& Srinivasan, S. (2012). Impact of Climate Change on the Indian Economy : Evidence from Foodgrain Yields (Issue 218).

Haile, M. G., Wossen, T., Tesfaye, K., \& von Braun, J. (2017). Impact of Climate Change, Weather Extremes, and Price Risk on Global Food Supply. Economics of Disasters and Climate Change, 1(1), 55-75. https://doi.org/10.1007/s41885-017-0005-2

Janjua, P. ., Samad, G., \& Khan, N. (2014). Climate Change and Wheat Production in Pakistan : An Autoregressive Distributed Lag Approach. NJAS - Wageningen Journal of Life Sciences, 68, 13-19. https://doi.org/10.1016/j.njas.2013.11.002

Kabubo-mariara, J., \& Karanja, F. K. (2007). The economic impact of climate change on Kenyan crop agriculture : A Ricardian approach. Global and Planetary Change, 57, 319-330. https://doi.org/10.1016/j.gloplacha.2007.01.002

Khanal, U., Wilson, C., Hoang, V., \& Lee, B. (2018). Farmers ' Adaptation to Climate Change, Its Determinants and Impacts on Rice Yield in Nepal. Ecological Economics, 144(July 2017), 139-147. https://doi.org/10.1016/j.ecolecon.2017.08.006

Klutse, N. A. B., Quagraine, K. A., Nkrumah, F., Quagraine, K. T., Berkoh-Oforiwaa, R., Dzrobi, J. F., \& Sylla, M. B. (2021). The Climatic Analysis of Summer Monsoon Extreme Precipitation Events over West Africa in CMIP6 Simulations. Earth Systems and Environment. https://doi.org/10.1007/s41748-021-00203-y

Korres, N. E., Norsworthy, J. K., Burgos, N. R., \& Oosterhuis, D. M. (2017). Temperature and drought impacts on rice production: An agronomic perspective regarding short- and long-term adaptation measures. Water Resources and Rural Development, 9, 12-27. https://doi.org/10.1016/j.wrr.2016.10.001

Kumar, A., Sharma, P., \& Joshi, S. (2015). Effects of Climatic Factors on Agricultural Productivity in India : A State-wise Panel Data Analysis. International Journal of Basic and Life Sciences, 3(1), 48-67.

Kumar, A., Singh, J., \& Sharma, P. (2020). Assessing the Climate Change Impact on Rice and Wheat Production in Uttar Pradesh and Haryana States of India. Climate Change, 6(21).

Kumar, K. S. K. (2011). Climate sensitivity of Indian agriculture : do spatial effects matter? Cambridge Journal of Regions, Economy and Society, 4(March), 221-235. https://doi.org/10.1093/cjres/rsr004 
472

473

Lal, M., Rathore, L. ., \& Anapalli, S. . (1998). Vulnerability of rice and wheat yields in NW India to future changes in climate. Agricultural and Forest Meteorology, 89(February), 101-114. https://doi.org/10.1016/S01681923(97)00064-6

Mishra, D., \& Chandra, N. (2016). Impact of climate change on agricultural production of Odisha ( India ): a Ricardian analysis. Regional Environmental Change, 16, 575-584. https://doi.org/10.1007/s10113-015-0774-5

Mitra, S. K. (2014). Nonlinear impact of rain on foodgrain production in India. Applied Economics Letters, 21(14), 1001-1005. https://doi.org/10.1080/13504851.2014.904483

Mohorji, A. M., Şen, Z., \& Almazroui, M. (2017). Trend Analyses Revision and Global Monthly Temperature Innovative Multi-Duration Analysis. Earth Systems and Environment, 1(1), 1-13. https://doi.org/10.1007/s41748-017-0014-x

Moses, J. A., Jayas, D. S., \& Alagusundaram, K. (2015). Climate Change and its Implications on Stored Food Grains. Agricultural Research, 4(1), 21-30. https://doi.org/10.1007/s40003-015-0152-z

Mukherjee, A., \& S.Huda, A. . (2018). Assessment of climate variability and trend on wheat productivity in West Bengal, India : crop growth simulation approach. Climate Change, 147, 235-252.

Nath, H. K., \& Mandal, R. (2018). Heterogeneous Climatic Impacts on Agricultural Production : Evidence from Rice Yield in Assam, India. Asian Journal of Agriculture and Development, 15 No.1, $23-42$.

Nath, P., \& Behera, B. (2011). A critical review of impact of and adaptation to climate change in developed and developing economies. Environment, Development and Sustainability, 13, 141-162. https://doi.org/10.1007/s10668-010-9253-9

Nsabimana, A., \& Habimana, O. (2017). Asymmetric effects of rainfall on food crop prices: evidence from Rwanda. Environmental Economics, 8(3), 137-149. https://doi.org/10.21511/ee.08(3-1).2017.06

Pal, D., \& Mitra, S. K. (2018). Asymmetric impact of rainfall on India's food grain production : evidence from quantile autoregressive distributed lag model. Theoretical Applied Climatology, 131, 69-76. https://doi.org/10.1007/s00704-016-1942-3

Pattanayak, A., \& Kumar, K. S. K. (2013). Weather Sensitivity of Rice Yield: Evidence from India (Issue September).

Pesaran.et.al. (2001). Bounds Testing Approaches to the Analysis of Level Relationships. 16(3), 289-326. https://doi.org/10.1002/jae.616

Pesaran, M. H., \& Shin, Y. (2002). LONG-RUN STRUCTURAL MODELLING. 4938(2002).

Praveen, B., \& Sharma, P. (2020). Climate Change and its impacts on Indian agriculture: An Econometric analysis. Journal of Public Affairs, 20(1). https://doi.org/10.1002/pa.1972 
Rashid, A., Alam, K., \& Gow, J. (2012). Exploring the relationship between climate change and rice yield in Bangladesh: An analysis of time series data. Agricultural Systems, 112, 11-16. https://doi.org/10.1016/j.agsy.2012.06.004

Rayamajhee, V., Guo, W., \& Bohara, A. K. (2020). The Impact of Climate Change on Rice Production in Nepal.

Res, C., Adams, R. M., Hurd, B. H., Lenhart, S., \& Leary, N. (1998). Effects of global climate change on agriculture : an interpretative review. 11, 19-30.

Sarker, M. A. R., Alam, K., \& Gow, J. (2019). Performance of rain-fed Aman rice yield in Bangladesh in the presence of climate change. Renewable Agriculture and Food Systems, 34(4), 304-312. https://doi.org/10.1017/S1742170517000473

Swaminathan, M. S., \& Kesavan, P. C. (2012). Agricultural Research in an Era of Climate Change. Agricultural Research, 1(1), 3-11. https://doi.org/10.1007/s40003-011-0009-z

Warsame, A. A. (2021). Climate change and crop production nexus in Somalia : an empirical evidence from ARDL technique.

Zakaria, A., Alhassan, S. I., Kuwornu, J. K. M., Azumah, S. B., \& Derkyi, M. A. A. (2020). Factors Influencing the Adoption of Climate-Smart Agricultural Technologies Among Rice Farmers in Northern Ghana. Earth Systems and Environment, 4(1), 257-271. https://doi.org/10.1007/s41748-020-00146-w 
Figures

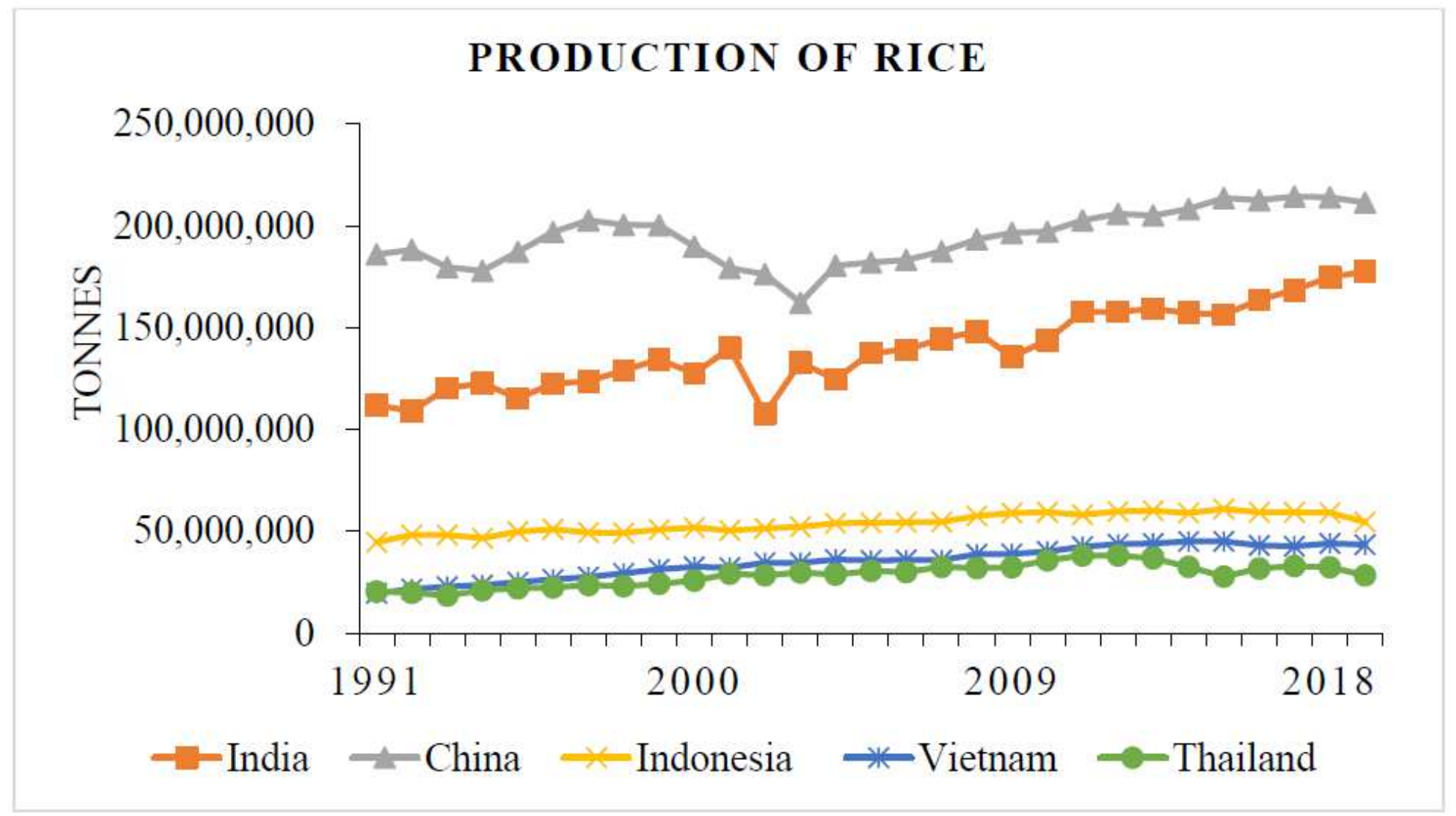

Figure 1

Trend of rice production in Asian countries 83 Sources: FAO 2019

\section{Annual Growth Rate}

30

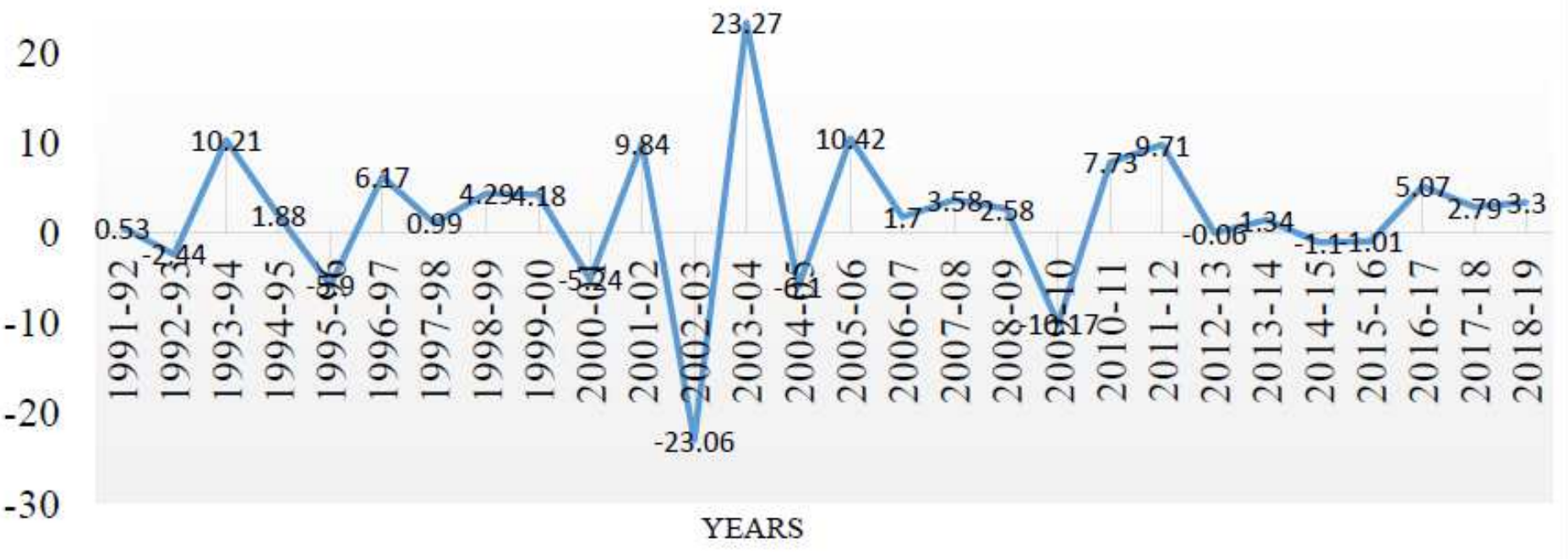


Annual Growth Rate of Rice Production in India Sources: CMIE Commodities (2019)
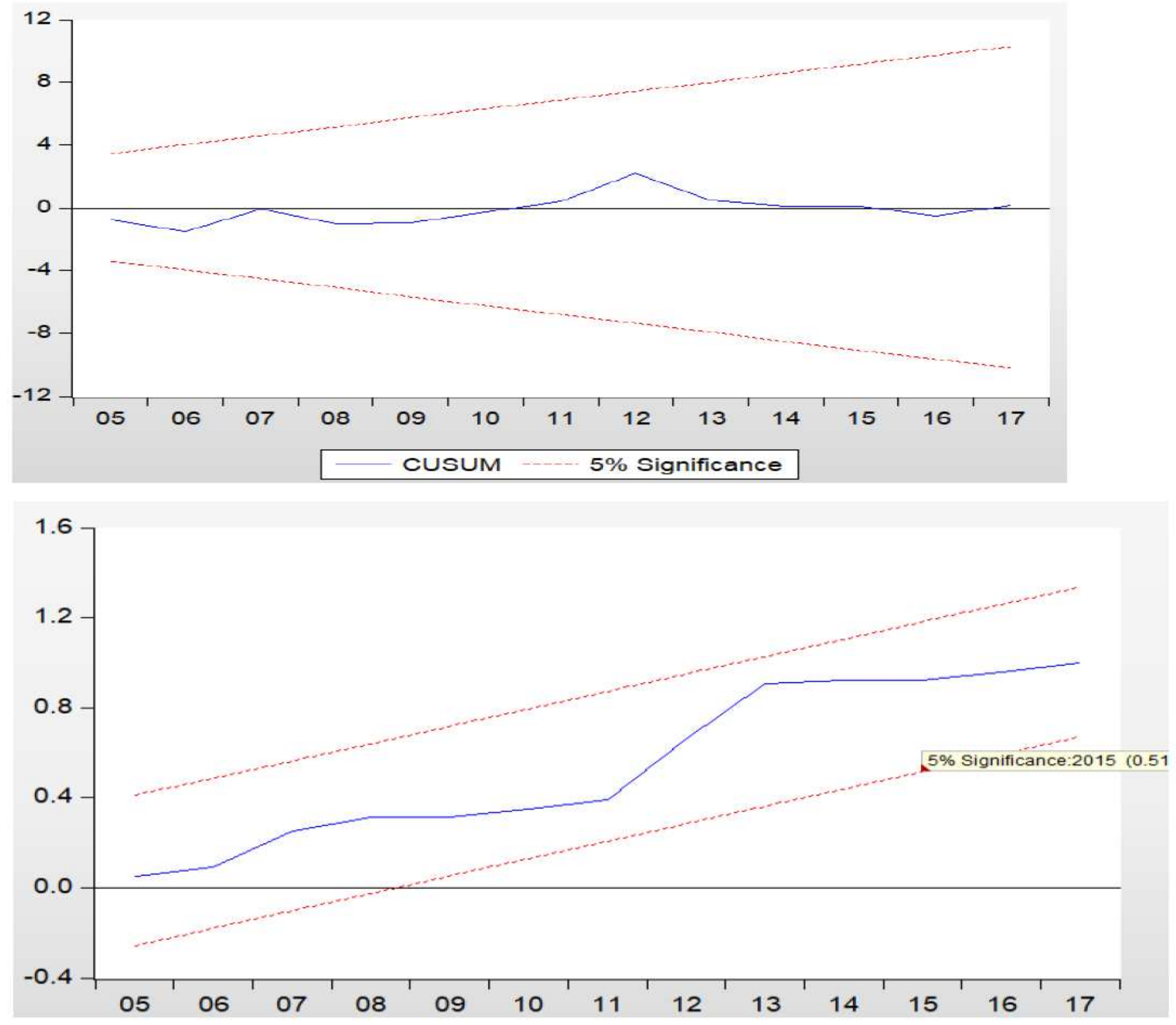

Figure 3

CUSUM and CUSUMQ square 


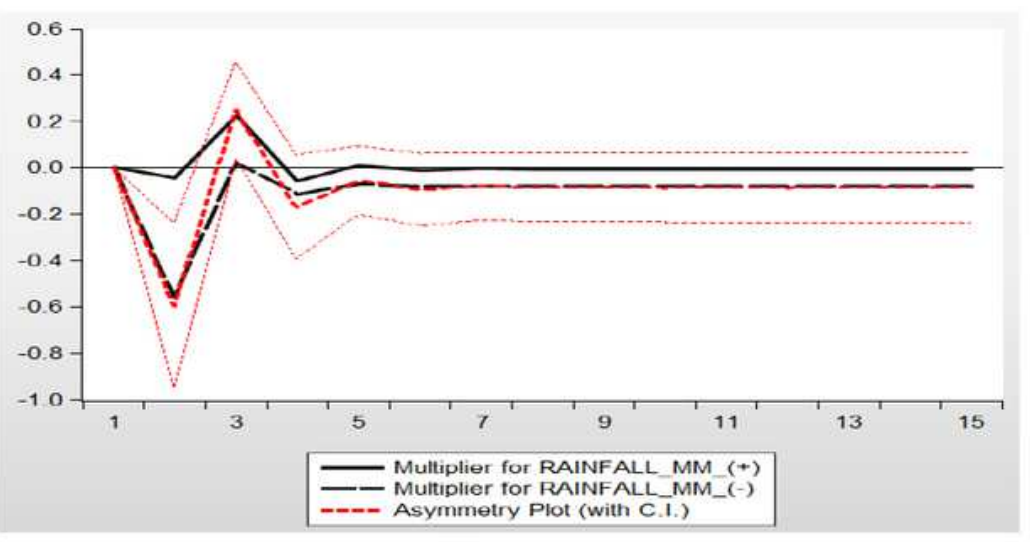

(a)

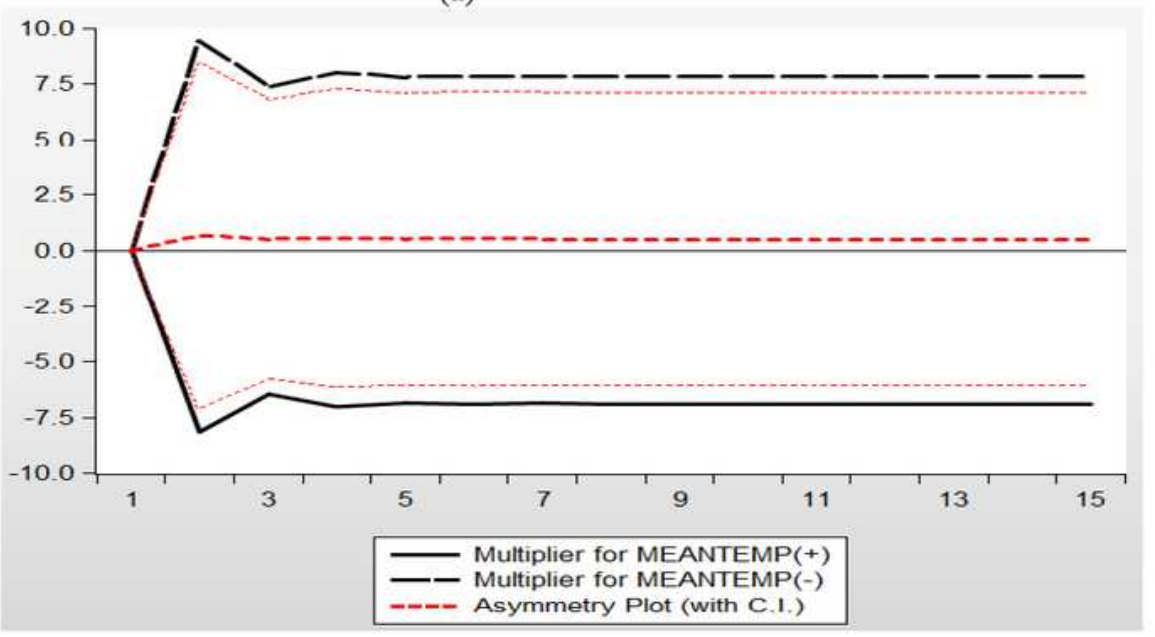

(b)

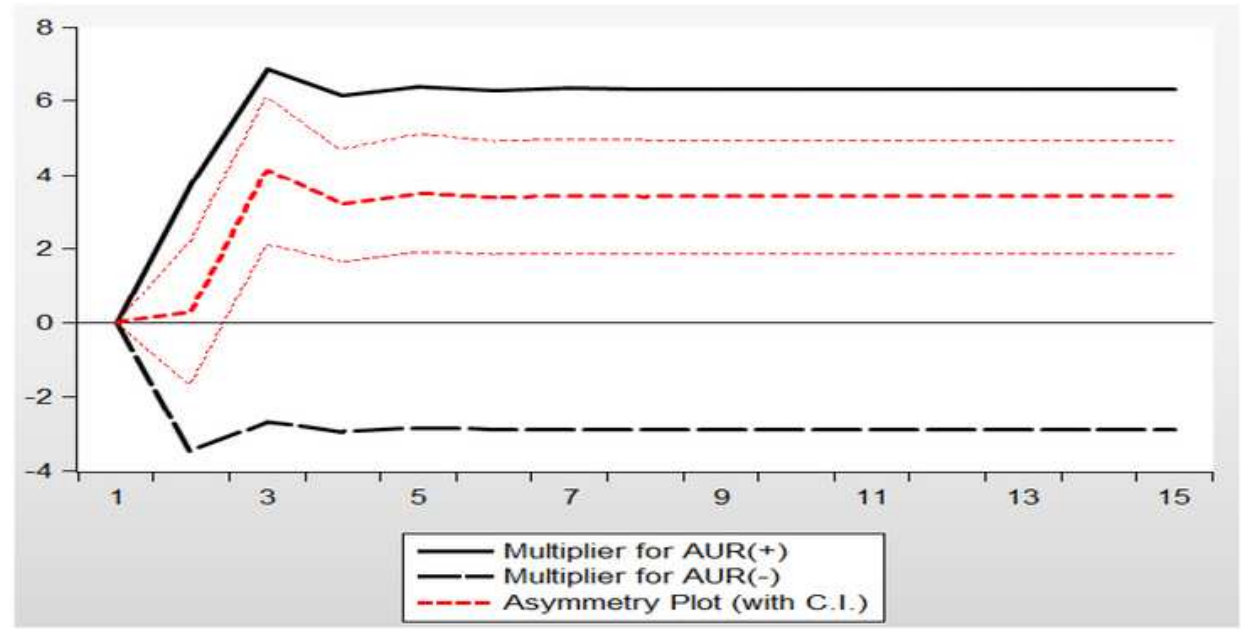

(c)

Figure 4

(a): Result of Dynamic Multiplier Graph (b): Result of Dynamic Multiplier Graph (C): Result of Dynamic Multiplier Graph 